\title{
Uma carioca exilada no Velho Mundo: deslocamentos poéticos de uma estrangeira bilíngue
}

\author{
Anselmo Peres Alós* \\ Universidade Federal de Santa Maria
}

\begin{abstract}
Resumo: Este trabalho busca realizar uma leitura do primeiro livro de poemas publicados por Diana Araújo Pereira - Outras palavras/Otras palabras (Rio de Janeiro: 7Letras, 2008) - obra que pode ser considerada como um exercício poético bilíngue, escrita por sua autora ao longo do período em que viveu em Sevilha, Espanha. A despeito de toda expectativa, os fragmentos de prosa poética desta obra não expressam uma visão facilista da subjetividade feminina, mas uma profunda especulação em torno das interconexões entre o ser mulher e a imaginação simbólica em torno das questôes da errância e do exílio, assim como da fragmentação do sujeito na prática da escrita literária em um espaço liminar marcado pela condição do migrante.
\end{abstract}

* Professor Adjunto do Departamento de Letras Vernáculas e do Programa de PósGraduação em Letras da Universidade Federal de Santa Maria. Coordenador do projeto de pesquisa Ressonâncias e dissonâncias do romance lusófono contemporâneo: o imaginário pós-colonial e a (des)construção da identidade nacional.

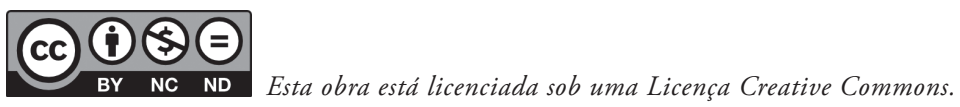


Palavras-chave: Escrita de autoria feminina. Imaginários da errância. Estrangeiridade.

\title{
Introdução
}

\author{
O caçador fala, \\ o marinheiro cala.
}

Um vive da morte emboscada, outro se amarra em cais de partida.

O homem faz amor

Para se sentir bem.

A mulher faz amor

Quando se sente bem.

Uns falam.

Outros apenas fogem do silêncio.

Uns amam.

Outros de si mesmos escapam.

(MIA COUTO, 2011, p. 19)

O tema da dissociação entre a essência e a aparência, o próprio e o alheio, o familiar e o estranho/estrangeiro, o eu e o outro é uma presença marcante e contínua na literatura ocidental. Esta presença já emerge na antiguidade clássica no mito de Narciso, seduzido pelo seu reflexo. Na literatura anglófona decadentista, Oscar Wilde tematiza a questão e atualiza o mito em The picture of Dorian Grey. Na poesia da brasileira Cecília Meireles, o tema será retomado em diversos poemas, tais como "Minha sombra" e "Mulher ao espelho" (incluídos em Mar 176 
absoluto e outros poemas - Retrato natural). De acordo com Yves-Alain Favre, "Narciso sabe [ou deveria saber] que a fusão entre ele e seu reflexo, entre o ser e o parecer, entre a essência absoluta e a aparência jamais será possível. A noite desce, a morte está próxima, o beijo dado na imagem se despedaça. Narciso deve desaparecer também" (FAVRE, 1997, p. 750).

O mito de Narciso relaciona-se com a temática do duplo, espécie de intuição arquetípica daquilo que mais tarde vai ser teorizado pela psicanálise freudiana a noção do Unreimlich, daquilo que é simultaneamente estranho e familiar, e que estará associado à questão das memórias traumáticas e à ideia de um sujeito clivado, retomado posteriormente por Jacques Lacan em sua leitura estruturalista da obra de Sigmund Freud (BRAVO, 1997, p. 261-287). Todavia, o imaginário em torno da constelaçáo simbólica do duplo e do mito de Narciso possuem uma característica estática, que pode até, em certo sentido, ser associada à esquize que caracteriza a subjetividade contemporânea, marcada pelos exílios (compulsórios ou voluntários) que caracterizam outra constelação imagética de importância contundente para a contemporaneidade: a da movência, da errância e do deslocamento:

Errante, um conceito que se forma do conhecimento de um céu ou de um destino; errante, associado ao próprio movimento da história humana; errante, como indissociável de um castigo cujas origens foram aproximadas aos mitos cósmicos: tais são os elementos heterogêneos que se acham hoje reunidos no complexo mito do Judeu Errante (ROUART, 1997, p. 665).

A figura do Judeu Errante, do estrangeiro sem rumo, condenado à vida eterna e a um eterno deslocamento, tem uma longa tradiçấo no imaginário ocidental, mas que, curiosamente, foi retomada pela literatura de maneira secundária: "a imagem de Ahasverus, o eterno errante, náo deu origem a narrativas míticas de primeira grandeza; as mais das vezes, serviu como fonte de uma porção de obras secundárias" (ROUART, 1997, p. 670). A imagem da errância desse eterno estrangeiro exprime "uma nostalgia, uma solidáo e uma insegurança que transformam sua 
silhueta didática de penitente contador de histórias, e da qual vai se apropriar o romantismo dos primeiros tempos" (ROUART, 1997, p. 666). A marcha do estrangeiro errante, sem destino e condenado a testemunhar dramaticamente cada novo ciclo da humanidade como castigo por ter desdenhado do sofrimento de Cristo atualiza o imaginário do confronto do humano frente ao Divino. Entretanto,

Descristianizado pelos filósofos racionalistas, ou transfigurado pela religião do futuro, esse homem inalcançável, o estrangeiro que somos para nós mesmos, tornou-se para muitos o discurso vivo da humanidade suspensa incessantemente entre o nada e a criação: ele recapitula em suas andanças as respostas individuais ou coletivas trazidas ao enfrentamento dramático do tempo mortal com a sede de eternidade" (ROUART, 1997, p. 671).

\section{As errâncias e a gênese da obra}

É com o nome de deusa caçadora da antiguidade latina, nome de deusa lunar, noturna e notívaga, que a fluminense Diana Araujo Pereira assina o seu primeiro livro de poemas, Outras palavras/Otras palabras, com sua primeira edição, bilíngue, publicada em 2008 pela Editora 7Letras, do Rio de Janeiro. Licenciada em Letras (português/espanhol), com mestrado, doutorado e pós-doutorado realizados em torno das literaturas hispânicas, com ênfase na poesia hispano-americana, atualmente Diana Araujo Pereira atua como professora e tradutora, lecionando literatura latino-americana na Universidade Federal da Integração Latino-Americana (UNILA), em Foz do Iguaçu, no Estado do Paraná. Como uma versão feminina do Judeu Errante, deslocandose entre rios e montes triplefronterizos, Diana Araujo Pereira coloca o desafio à autoridade divina como conditio sine qua non para alcançar 
a expressão poética de sua própria escrita: "Aprendi a escrever quando parei de rezar" (PEREIRA, 2008, p. 412).

Outras palavras/Otras palabras, um pequeno compêndio de fragmentos de prosa poética, é fruto de uma temporada de errância e de exílio voluntário da autora, entre 2005 e 2006, na cidade de Sevilha, na Espanha. Escrito originalmente em espanhol, foi posteriormente traduzido, pela própria autora, para o português. Esta gênese intercultural, marcada pelo exercício da escritura em uma língua outra, estranha e estrangeira, cruza os impromptus líricos da escritora, marcando sua escrita, da primeira à última linha, com as preocupaçóes envolvendo a dialética identidade/alteridade. Nesta dialética, uma das primeiras questôes que salta à vista é o estranhamento que o eu-lírico enfrenta em seu confronto diário com a língua espanhola, buscando sua própria identidade em uma terra estranha e expressando-se na língua do outro: “[e]screvo da beira de um nome que não é o meu. Com a pretensão e a soberba de quem já leva consigo um nome próprio e seu e se sente à vontade, e se vê em cada letra ou som" (p. 13).

É possível reconhecer, na escrita poética de texto de Diana Araujo Pereira, que o processo de escrita poética emerge simultânea e paradoxalmente como busca e problematização da identidade do sujeito feminino contemporâneo, que se faz presente de ponta a ponta de seu livro. $\mathrm{O}$ ato de escrever aparece como necessidade que ultrapassa todas as barreiras impostas pelo idioma, ou quase todas, como pode ser observado em: "[p]orque não se esqueçam que as mãos sim são minhas, ainda que de nada me sirvam se eu não puder escrever, se me falharem os nomes" (p. 13).

O trabalho de escritura é encarado pela poeta como um salto no escuro, enfrentamento do abismo semântico que por vezes assalta o indivíduo que habita a contemporaneidade: "[e]screvo minhas linhas saltadas sobre o vazio” (p. 13). É no fazer literário que o eu-lírico projeta

\footnotetext{
${ }^{2}$ Todas as referências a este livro, daqui em diante, serão feitas retomando apenas o número da página citada.
} 
o espaço de constituição de sua subjetividade. O fazer poético, mais do que um espaço de artesanato e artifício estético, é o palco no qual são encenados os pequenos dramas do cotidiano: "[e]screvo meus contos de amor, meus sonetos de inverso, minhas tertúlias mais trágicas. E de um ou outro nome me defendo melhor ou pior, mas escrevo" (p. 13). O exercício de especulação racional, por outro lado, é visto como uma aporia, um tropo indecidível que coloca o sujeito entre o prazer da especulação intelectual e o risco do ostracismo advindo dessa mesma especulação: " $[\mathrm{m}]$ e divirto ao filosofar, mesmo que sirva apenas para me aproximar ainda mais do meu beco sem saída” (p. 14).

A poética de Diana Araujo Pereira está marcada por esta busca de sentido, ou melhor, pela busca do sentido de si. Este sentido não é fruto de momentos epifânicos ou da inspiração sagrada das musas; pelo contrário, o fazer poético é encarado aqui como labor, como trabalho, como resultado do esforço humano, e tal posicionamento pode ser vislumbrado pelas metáforas utilizadas pela autora. Talvez a mais significativa dessas metáforas que fazem emergir o valor da palavra poética como fruto do trabalho de um sujeito historicamente situado esteja na analogia que se faz entre as palavras e a fornada de pães: "[a] fornada de novas palavras cheira na rua distante" (p. 28).

A busca interminável pelo sentido náo é tanto um esforço hermenêutico de compreensão do mundo, mas sim um esforço intelectual pela constituição de si, e esta busca também aproxima o fazer poético da imagem do trabalho artesanal: "[e]screvo de dentro da fome, da dor e da morte. Escrevo de dentro da perda de sentido” (p. 15). Tentativa de apreender, em um átimo do tempo da enunciação poética, uma provisória imagem estática dessa identidade permanentemente em processo de transformação. Daí o processo metonímico que associa o nome próprio à identidade: “[e]m que abismos nos lançamos à vertigem de nosso nome? E acaba que tudo é em vão. Porque a palavra sagrada, a que te situa, sempre desaparece como uma miragem sonora, como o sabor de paraíso que se assoma nos lábios, mesmo que você nunca o tenha provado" (p. 16). 


\section{A condição de estrangeira}

O embate com o estranho e com o diferente, com o outro e com o estrangeiro, sempre foi marcado pelo conflito e pela complexidade. Todavia, neste início de século XXI, em um contexto planetário no qual não são raros os conflitos beligerantes de alcance internacional em função da xenofobia, dos fundamentalismos e da intolerância, tornase salutar a colocação em discurso do tema da alteridade: "[a] terra me devolve suas recordaçôes, náufragas, nós duas, entre tantos mares” (p. 22). A mudança radical na percepção do tempo e da velocidade, nos meios de comunicação, também impactam profundamente a maneira do sujeito contemporâneo de lidar com as trocas e os fluxos de informação: “[a]s palavras te olham através das redes que conformam os mapas. Te exalam entre luz e silêncio, entre o todo e as partes" (p. 29). A mundialização da cultura e as novas ferramentas de comunicação ampliaram infinitamente nossos horizontes e, curiosamente, trouxeram o outro para mais perto de nós.

Diana Araujo Pereira não está alheia a estas questóes na sua produção poética: "[t]ocar o outro, cheirá-lo, esvaziar-se e voltar a encher-se na amizade ou no ódio. Signos contrários da mesma e intrínseca necessidade angustiante. Odiar o outro é odiar a si mesmo pela incapacidade de ser inteiro" (p. 17). As indagaçóes líricas da autora nos jogam ainda para outra dimensão da alteridade, que remonta a Estrangeiros para nós mesmos, de Julia Kristeva: o outro que em nós habita, e a inevitável errância do eu-lírico em busca de sentido para o absurdo do real: "[s] ou a deusa sonhada pela minha própria alegria, e a estranha cerva que percorre as matas" (p. 29). Em certa medida, a voz da poeta alcança uma dialética do equilíbrio, contornando a inevitável violência que marca o encontro do eu com o estrangeiro que o habita. Para Kristeva, a imagem do estrangeiro e a condição de "estrangeiridade" inevitavelmente apontam para a condição cindida do sujeito da contemporaneidade: 
Estrangeiro: raiva estrangulada no fundo de minha garganta, anjo negro turvando a transparência, traço opaco, insondável. Símbolo do ódio e do outro, o estrangeiro não é nem a vítima romântica de nossa preguiça habitual, nem o intruso responsável por todos os males da cidade. Nem a revelação a caminho, nem o adversário imediato a ser eliminado para pacificar o grupo. Estranhamente, o estrangeiro habita em nós (KRISTEVA, 1994, p. 9).

A palavra poética trabalhada pela autora recupera o leitor da apatia e do atordoamento gerados pela repetição mecânica do cotidiano: "[n]ormalmente somos sonolentos, até que somos acordados pelas taquicardias de algumas palavras” (p. 33). É a consciência de se utilizar da palavra do outro e da língua espanhola, em terras europeias, para encontrar, construir e desvelar seu próprio universo semântico que coloca a poesia da autora em diálogo profícuo com o pensamento estético e político latino-americano. Ao ler que "[m]inhas vidas vividas em sílabas alheias, em balbucios que se somam ao longo do ciclo" (p. 35), torna-se impossível não estabelecer uma conexão intertextual que carrega o leitor, partindo do lirismo de Outras palavras e chegando até o pensamento de Hugo Achugar (2006), na ocasião em que o poeta uruguaio problematiza a possibilidade de uma epistemologia latino-americana, ao perguntar se, na América Latina, a permanência residual do colonialismo não estaria condenando os pensadores a um mero balbucio teórico: "[s]angra a escuridão para tirar proveito da manhã. Desfiar os discursos atados, para que as palavras respirem a alteridade" (p. 35).

Balbucio teórico é a expressão articulada por Hugo Achugar para se referir ao discurso teórico latino-americano e ao seu histórico de incompreensão à crítica europeia e estadunidense. A expressão decorre do não reconhecimento imputado a esse discurso, assim como do fato de que tal discurso articula resíduos culturais intraduzíveis para o olhar exógeno ao contexto cultural latino-americano. Essa língua "balbuciante" deixa de acolher os termos totalizantes da crítica e da teoria eurocêntricas, e abre espaço para a permanência da tensão promovida pela ambivalência 
e pela indecidibilidade ${ }^{3}$ radicais que se fazem presentes quando se tenta interpretar o "outro", ato criativo pelo qual se tateia o que é estranho, o que é de fora, o que é estrangeiro.

Finalmente, diante desta proposta poética, que é simultaneamente estética e política, não causa estranhamento que a edição final de Outras palavras/Otras palabras saia em formato bilíngue. Tal como afirma Sara Viola Rodrigues, "a tradução, essa 'ponte necessária', na definição de José Paulo Paes (1990), continua sendo, nesse início de século, um desafio o enorme. Agora ainda mais, com a conscientizaçáo crescente - embasada nos estudos teóricos - sobre a responsabilidade de promover a leitura do Outro a partir de uma matriz dialógica que lhe preserve a identidade" (RODRIGUES, 2010, p. 195).

Uma das recorrências mais marcantes na cena poética contemporânea é a temática do desmantelamento do centro e do mito de um suposto sujeito universal. Uma das primeiras manifestações pósestruturalistas a questionar a dinâmica da significação baseada em um centro estável foi Jacques Derrida (1971). Retomando a discussão sobre a desestabilização do centro estrutural na constituição das subjetividades contemporâneas, a canadense Linda Hutcheon (1991) aponta para a emersão do que ela chama de "subjetividades excêntricas", características daqueles sujeitos aqueles que não estão mais, ou nunca estiveram, no centro ocupado pelo mito de um sujeito universal, sinalizando, contudo, a sua permanência residual nas práticas culturais de significação pósmodernas como uma ficçấo de ordem: "[...] o centro não pode permanecer, mas ainda é uma atraente ficção de ordem e unidade que a arte e a teoria pós-modernas continuam a explorar e a subverter" (HUTCHEON, 1991, p. 88).

\footnotetext{
${ }^{3} \mathrm{O}$ indecidivel é aquilo "que habita as oposiçôes conceituais como, no exemplo, que estamos tratando aqui, fala/escrita, significante/significado etc., tornando-as possível, sem, contudo, se deixar compreender por elas ou, através delas, vir a constituir dialeticamente um terceiro termo" (DUQUE-ESTRADA, 2002, p. 13.
} 


\section{Referências}

ACHUGAR, Hugo. Planetas sem boca: escritos efêmeros sobre arte, literatura e cultura. Trad. Lisley Nascimento. Belo Horizonte: UFMG, 2006.

ALÓS, Anselmo Peres e WOITECHUMAS, Régis. Quando Cecília se completa: sombra, o retrato e a busca transcendental da unidade subjetiva. In: MELLO, Ana Maria Lisboa de (Org). Cecília Meireles \& Murlo Mendes. Porto Alegre: Uniprom, 2002. p. 144-150.

BRAVO, Nicole. Duplo. In: BRUNEL, Pierre (Org.). Dicionário de mitos literários. Trad. Carlos Sussekind et alli. Rio de Janeiro: José Olympio; Brasília: Editora UnB, 1997. p. 261-288.

COUTO, Mia. Falas de uns. In: . Tradutor de chuvas. Maputo: Ndjira, 2011. p. 19.

DERRIDA, Jacques. A estrutura, o signo e o jogo nas ciências humanas. In: . A escritura e a diferença. São Paulo: Perspectiva, 1971. p. 227-249.

DUQUE-ESTRADA, Paulo. Às margens: a propósito de Derrida. São Paulo: Loyola, 2002.

FAVRE, Yves-Alain. Narciso. In: BRUNEL, Pierre (Org.). Dicionário de mitos literários. Trad. Carlos Sussekind et alli. Rio de Janeiro: José Olympio; Brasília: Editora UnB, 1997. p. 747-750.

HUTCHEON, Linda. Poética do pós-modernismo: história, teoria, ficção. Tradução de Ricardo Cruz. Rio de Janeiro: Imago, 1991.

KRISTEVA, Julia. Estrangeiros para nós mesmos. Trad. Maria Carlota Carvalho Gomes. Rio de Janeiro: Rocco, 1994.

MEIRELES, Cecília. Mar absoluto e outros poemas - Retrato natural. Rio de Janeiro: Nova Fronteira, 1983.

PEREIRA, Diana Araujo. Outras palavras/Otras palabras. Rio de Janeiro: 7Letras, 2008. (Ediçáo bilíngue português/espanhol). 
RODRIGUES, Sara Viola. Questôes teórico-críticas e metodológicas dos estudos de tradução na contemporaneidade. In: SCHMIDT, Rita Terezinha (Org.). Sob o signo do presente: intervençóes comparatistas. Porto Alegre: Editora da UFRGS, 2010. p. 191-202.

ROUART, Marie-France. O mito do Judeu Errante. In: BRUNEL, Pierre (Org.). Dicionário de mitos literários. Trad. Carlos Sussekind et alli. Rio de Janeiro: José Olympio; Brasília: Editora UnB, 1997. p. 665-672.

WILDE, Oscar. Complete works of Oscar Wilde. Glasgow: Harper Collins, 1994.

[Texto recebido em junho de 2013 para compor a corrente edição especial]

\section{A carioca writer exiled in the Old World: foreign bilingual's poetic displacements}

Abstract: this paper aims at analizing the very first literary book published by Diana Arajo Pereira - entitled Outras palavras/Otras palabras (Rio de Janeiro: 7Letras, 2008) - a bilingual exercise on poetic writing writen by its author during a period in with she lived in Sevillha, Spain. Despite of all expectative, the Pereira's poetical fragments do not expresses a easy view of the feminine subjectivity, but a deep speculation around the interconnections between the condition of being a woman and the symbolic imagination around the wandering and the exiles of the self as well as the fragmentation of the self in the practice of literary writing signed by the migrant condition.

Keywords: Woman's writing. Imaginaries of the wandering. Foreignness.

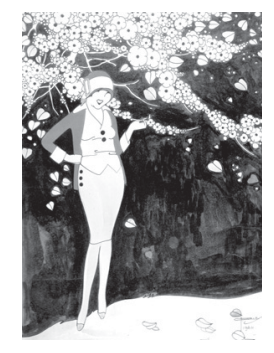


